\title{
The Memokath-051 Stent for the Treatment of Ureteric Obstruction: A NICE Medical Technology Guidance
}

\author{
Emily Eaton Turner ${ }^{1} \cdot$ Michelle Jenks $^{1} \cdot$ Rachael McCool $^{1} \cdot$ Chris Marshall $^{1} \cdot$ \\ Liesl Millar $^{2} \cdot$ Hannah Wood ${ }^{1}$ Alison Peel ${ }^{1} \cdot$ Joyce Craig $^{1}$ - Andrew J Sims ${ }^{3,4}$
}

Published online: 3 April 2018

(C) The Author(s) 2018

\begin{abstract}
Memokath-051 is a thermo-expandable, nickeltitanium alloy spiral stent used to treat ureteric obstruction resulting from malignant or benign strictures. The National Institute for Health and Care Excellence (NICE) selected Memokath-051 for evaluation. The company, PNN Medical, claimed Memokath-051 has clinical superiority and cost savings compared with double-J stents. It identified five studies reporting clinical evidence on Memokath-051 and constructed a de novo cost model comparing Memokath-051 to double-J stents. Results indicated that Memokath-051 generated cost savings of $£ 4156$ per patient over 2.5 years. The External Assessment Centre (EAC) critiqued the company's submission and completed substantial additional work. Sixteen studies were identified assessing Memokath-051 and all listed comparators in the scope (double-J stents, reconstructive surgery and metallic and alloy stents) except nephrostomy. Similar success rates were reported for Memokath-051 compared with double-J
\end{abstract}

Electronic supplementary material The online version of this article (https://doi.org/10.1007/s40258-018-0389-3) contains supplementary material, which is available to authorized users.

Emily Eaton Turner

emily.eatonturner@york.ac.uk

1 York Health Economics Consortium, Enterprise House, Innovation Way, University of York, Heslington, York, YO10 5NQ, UK

2 National Institute for Health and Care Excellence, Level 1A, City Tower, Piccadilly Plaza, Manchester M1 4BT, UK

3 Newcastle Upon Tyne Hospitals NHS Foundation Trust, Freeman Hospital, Freeman Road, Newcastle upon Tyne NE7 7DN, UK

4 Faculty of Medical Sciences, Institute of Cellular Medicine, University of Newcastle Upon Tyne, Newcastle upon Tyne NE1 7RU, UK and Resonance stents and worse outcomes compared with other options with evidence available. The EAC updated the company's cost model structure and modified several inputs. The EAC's model estimated that Memokath-051 generated savings of at least $£ 1619$ per patient over 5 years compared with double-J stents, was cost neutral compared with other metallic stents and was cost saving compared with surgery up to month 55 . Overall, Memokath-051 is likely to be cost saving in patients not indicated for reconstructive surgery and those expected to require a ureteral stent for at least 30 months. The Medical Technologies Advisory Committee (MTAC) reviewed the evidence and supported the case for adoption, issuing partially supportive recommendations published after public consultation as Medical Technologies Guidance 35. 


\section{Key Points for Decision Makers}

The case for adopting Memokath-051 compared with double-J stents for treating ureteric obstruction is partially supported by evidence.

The evidence is limited but suggests that in selected patients, Memokath-051 is effective at relieving ureteric obstruction and improving quality of life. When inserted by clinicians trained in using Memokath-051 specifically and in appropriate patients, Memokath-051 is associated with equivalent success rates and a better patient experience compared with double-J stents.

The cost consequences of adopting Memokath-051 are uncertain. However, when used in appropriate patients and by clinicians trained in its use, potential cost savings resulting from fewer repeat procedures may arise with Memokath-051.

The key challenges of the assessment resulted from the poor quality and quantity of available evidence and therefore uncertainty in conclusions.

\section{Introduction}

Novel and innovative medical devices and diagnostics can be evaluated to support evidence-based medical technologies guidance produced by the National Institute for Health and Care Excellence (NICE). Where appropriate, this can encourage adoption of the medical devices and diagnostics within the National Health Service (NHS) in England. Companies may notify technologies to NICE. NICE also identifies topics from a variety of sources, including NHS England and horizon scanning organisations. Selecting which technologies to evaluate uses criteria including the potential to offer clinical benefits to patients and the NHS, and/or to reduce costs, compared with standard care. The Medical Technologies Advisory Committee (MTAC) develops guidance following independent assessment of the clinical and economic evidence submitted by the company, conducted by an External Assessment Centre (EAC), and after a public consultation period. The Medical Technologies Evaluation Programme (MTEP) methodology is described in detail by Campbell and Campbell [1].

In February 2018, NICE issued final guidance on Memokath-051 for treating ureteral obstruction. Memokath-051 is a single-use, thermo-expandable, nickel-titanium alloy spiral stent [2]. The EAC critiquing the evidence was the Newcastle upon Tyne Hospitals NHS Foundation Trust and
York Health Economics Consortium partnership. Clinical experts, identified using NICE's published processes [3], provided advice to the EAC and MTAC.

This article is one of a series of Medical Technology Guidance summaries published by this journal. It includes an overview of the clinical and economic benefits of Memokath-051 as reported in the company's submission, the EAC's assessment report [4] and the subsequent development of the NICE guidance [5]. The NICE website provides full documentation of the process, supporting evidence and the final guidance [5].

\section{Background to the Indication and Devices}

The ureter is a narrow muscular duct that urine flows through from a kidney to the bladder [6]. A ureteric stricture is characterised by a narrowing of the ureter and can have malignant or benign causes. When the ureter is obstructed, the normal flow of urine from the kidney to the bladder is disrupted, which can lead to complications associated with the kidney and urinary tract. Irrespective of the cause of the stricture, it is necessary to relieve the obstruction in the ureter [6]. Memokath-051 is inserted into the ureter. The thermo-sensitive 'shape memory' of the stent softens it in the pre-insertion state, but once inserted and heated, the distal end of the stent (or both ends if a double cone design) returns to a preformed cone shape, which anchors the stent into position within the ureter. The stent then keeps the ureter open [7,8].

The assessment of Memokath-051 was conducted for the indications of benign or malignant strictures in line with the scope produced by NICE [9]. The patient population receiving treatment for ureteric stricture is heterogeneous (i.e. differing degrees of underlying disease severity, patient condition and life expectancy). Clinical experts advised that when a patient has a malignant stricture, the type of cancer determines life expectancy. Therefore, the functional lifetime of the stent depends on the life expectancy of the patient rather than the degree of the stricture. The life expectancy of patients with malignant ureteral obstruction is poorly reported in the literature, but median estimates of less than 1 year [10] and 3.7-15.3 months have been reported [11]. The life expectancy of patients with benign strictures would not usually be limited by the aetiology of the stricture, but rather is expected to align with that for a matched group in the general population.

In the NHS, people with ureteric obstruction are generally treated in secondary care. Stents can be inserted into the ureter either by an antegrade or retrograde procedure where the stent is inserted via the bladder or via the kidney, respectively. Clinical experts advised that the method selected is based on ureteric anatomy, reconstruction and 
tolerability of the bladder component stent. Antegrade insertion is used if retrograde access fails. The procedure is conducted by a urologist or radiologist, typically in an operating theatre under general anaesthetic, but can be done under local anaesthetic. Following the stenting procedure, patients typically attend three follow-up appointments in the year following insertion. There are multiple surgical options available to patients with ureteric strictures: ureteric re-implantation into the bladder, balloon dilation, laser endopyelotomy and extra-anatomical bypass. Depending on the type of reconstructive surgery, the procedure can be conducted as either open or laparoscopic surgery. An expert advised that as part of reconstructive surgery, patients have a double-J stent inserted. This is removed a few weeks after surgery once healing has occurred.

Data from the Hospital Episode Statistics (HES) database for England show that in 2014-2015 there were 7674 retrograde insertions, 2733 retrograde removals of ureteric stents, 80 cases of percutaneous insertions (i.e. antegrade insertions) and 22 replacements of ureteric metallic stents [12]. These data are for all available stent types, with no information available on the type of stent used or the reason for stenting.

Stenting using devices such as Memokath-051 is intended to offer immediate relief of the patient's symptoms. The principle purpose of reconstructive surgery is to remove the obstruction. Clinical experts advised that patients who can tolerate surgery, mainly those with benign strictures, should be referred to a tertiary centre. A claimed benefit of the Memokath-051 stent over comparator stents is that it requires less frequent replacement. Clinical experts noted that double-J stents can remain in situ for up to 6 months before they must be removed or replaced. For metallic stents, the time they can remain in situ varies from 12 months for Resonance [13] to 18 months for UVENTA [14] and 3 years for Allium [15]. Some studies report Memokath-051 indwelling times of up to 4 years [16, 17].

The scope [9] defined the relevant comparators to Memokath-051 as other stent types (double-J stents and alloy or metallic stents), nephrostomy and reconstructive surgery. The decision problem addressed by the company and EAC and how these compare to the scope is now described.

\section{Decision Problem (Scope)}

\subsection{Population}

The population described in the scope [9] was people with ureteric obstruction as a result of malignant or benign strictures. The company did not include evidence that included patients with only malignant or only benign strictures, but the EAC identified and included studies that made reference to malignant stricture, benign stricture or both. Subgroups were also specified, including people unfit for surgery, those with a malignant stricture or a benign stricture, either antegrade or retrograde insertion, and the procedure being performed by an interventional radiologist or urologist. Subgroup analysis was not conducted by the company. The EAC identified limited clinical evidence on the subgroup of benign versus malignant stricture, but there was a paucity of information to inform other subgroup analyses.

\subsection{Intervention}

The intervention specified in the scope and matched by the company's submission was 'Memokath-051' [9].

\subsection{Comparator}

Four comparators were specified in the scope: double-J stents, nephrostomy, reconstructive surgery and metallic and alloy stents [9]. In the NHS, there are numerous varieties of double-J stents available [18]. This analysis is not specific to a particular double-J stent. The EAC identified three metallic or alloy stents available in the NHS, namely, UVENTA, Allium and Resonance. Clinical experts advised that the following surgical options are available to patients with ureteric strictures: ureteric reimplantation into the bladder, balloon dilation, laser endopyelotomy, extra-anatomical bypass and ileal ureter replacement (IUR). The company compared Memokath051 with double-J stents only. The EAC identified evidence for UVENTA, Allium, Resonance, double-J and IUR. No evidence comparing Memokath-051 to nephrostomy was identified; hence a comparison of clinical and cost-effectiveness was not possible.

\subsection{Outcomes}

Ten outcomes were specified in the scope [9]. The company presented data in relation to all of the outcomes reported in the identified studies rather than those relevant to the decision problem. The company did not attempt to synthesise the outcomes reported across the trials. The EAC reported on all the outcomes, including those relating to complications, using the results from clinical studies judged to have acceptable levels of external validity. In the economic submission, the company addressed 3 outcomes, namely the number and rate of replacement stents, the length of time the stent remains in situ and the number and rate of repeat procedures. The EAC included more outcomes in its economic model. 


\section{Review of Clinical and Economic Evidence}

Section 4.1 summarises the clinical evidence submitted, the EAC's critique and the EAC's additional work. Section 4.2 provides the same detail for the economic evidence.

\subsection{Clinical Effectiveness Evidence}

\subsubsection{Company's Review of Clinical Effectiveness Evidence}

The company searched for clinical evidence relating to the decision problem and identified 23 papers for full-text review, of which six publications describing five studies were included in the submission. One of these, a nonrandomised, open-label study comparing Memokath-051 with double-J stents was reported as a clinical trial record only [19]. Two were single-arm, observational studies $[2,20,21]$, one of which was reported in two publications $[2,21]$. A further observational study investigating Memokath-051 identified by the company [22] could not be found by the EAC. The final included paper reported on a comparative study of Memokath-051 versus double-J stents [7]. However, the company reviewed a different paper reporting only data from the subgroup of patients that received Memokath-051 from this study [23].

The company only partially completed the results table for each included study and did not attempt to synthesise the outcomes reported across the trials.

\subsubsection{Critique of Clinical Effectiveness Evidence}

The EAC planned to critique the company's literature search, evidence selection and quality assessment of included studies. However, the description of the search methodology was limited and not sufficient to accurately replicate or evaluate the company's search. Further, the company's selection criteria were not deemed appropriate to identify all the studies relevant to the scope. Therefore, the EAC undertook a de novo literature search and revised the selection criteria to identify relevant clinical evidence on Memokath-051. The EAC's search strategies are described in the EAC's assessment report [4].

The EAC identified 1274 unique records, which were assessed by two reviewers (Fig. 1). Due to the number of studies meeting the EAC's selection criteria, single-arm studies reported in abstracts only (i.e. no full text available) were excluded. Abstracts reporting comparative studies were eligible for inclusion due to the paucity of published comparative evidence. Sixteen studies, reported in 22 publications, were eligible for inclusion in the review.
These included all but one of the studies included in the company's review. However, an updated version of the same study was identified by the EAC [24] and included in its review. The EAC identified six comparative studies (of which two were reported as full-text publications [7, 25], three were conference abstracts [26-28] and one was presented in a clinical trial record and an abstract $[17,19])$ and ten single-arm, observational studies (each published as full text) [16, 20, 21, 24, 29-34].

The comparative studies deemed eligible for inclusion by the EAC are summarised in Table 1, and the single-arm studies are summarised in the supplementary table (see the electronic supplementary material).

The EAC critically appraised the internal and external validity of three comparative studies $[7,19,25]$ and ten single-arm studies [16, 20, 21, 24, 29-34] (abstracts could not be critically appraised due to insufficient information). Two comparative studies provided acceptable levels of internal validity $[7,25]$, whilst one study was considered to have low internal validity [19]. All of the comparative studies provided acceptable levels of external validity and, therefore, were considered applicable to the scope and acceptable in terms of generalisability [7, 19, 25]. The single-arm studies generally had low levels of internal validity; however, their external validity was enhanced by the fact they were observational studies and, therefore, may reflect clinical practice better than a strictly protocol-driven trial. Two single-arm studies $[16,31]$ did not provide acceptable levels of internal or external validity and were excluded from further consideration.

Reporting on the outcomes was generally poor across all the included studies. The most common outcomes reported were clinical success and rates of migration. Clinical success, however, was not consistently defined across the studies, which meant statistical pooling could not be conducted. In the comparative studies, Memokath051 had a lower clinical success rate than Allium stents (81 vs $100 \%$ ) [27], UVENTA (43 vs $82 \%, p=0.31$ ) [25] and IUR (35 vs $89 \%$ ) [26], but was comparable with double-J stents (100\% success rate in both arms) [17] and Resonance stents (82 and $86 \%$ for Memokath-051 and Resonance stents, respectively) [28]. Only one study reported details of statistical significance [25] and found that the difference observed between UVENTA and Memokath-051 was not statistically significant [25]. Five comparative studies reported on stent migration, and in all cases, migration was more common for Memokath-051 than the comparator [7, 25-27]. Memokath-051 is judged acceptable to patients, and evidence from a well conducted study with acceptable external validity supports improved quality of life [7]. The results extracted by the EAC are presented in Table 2. 


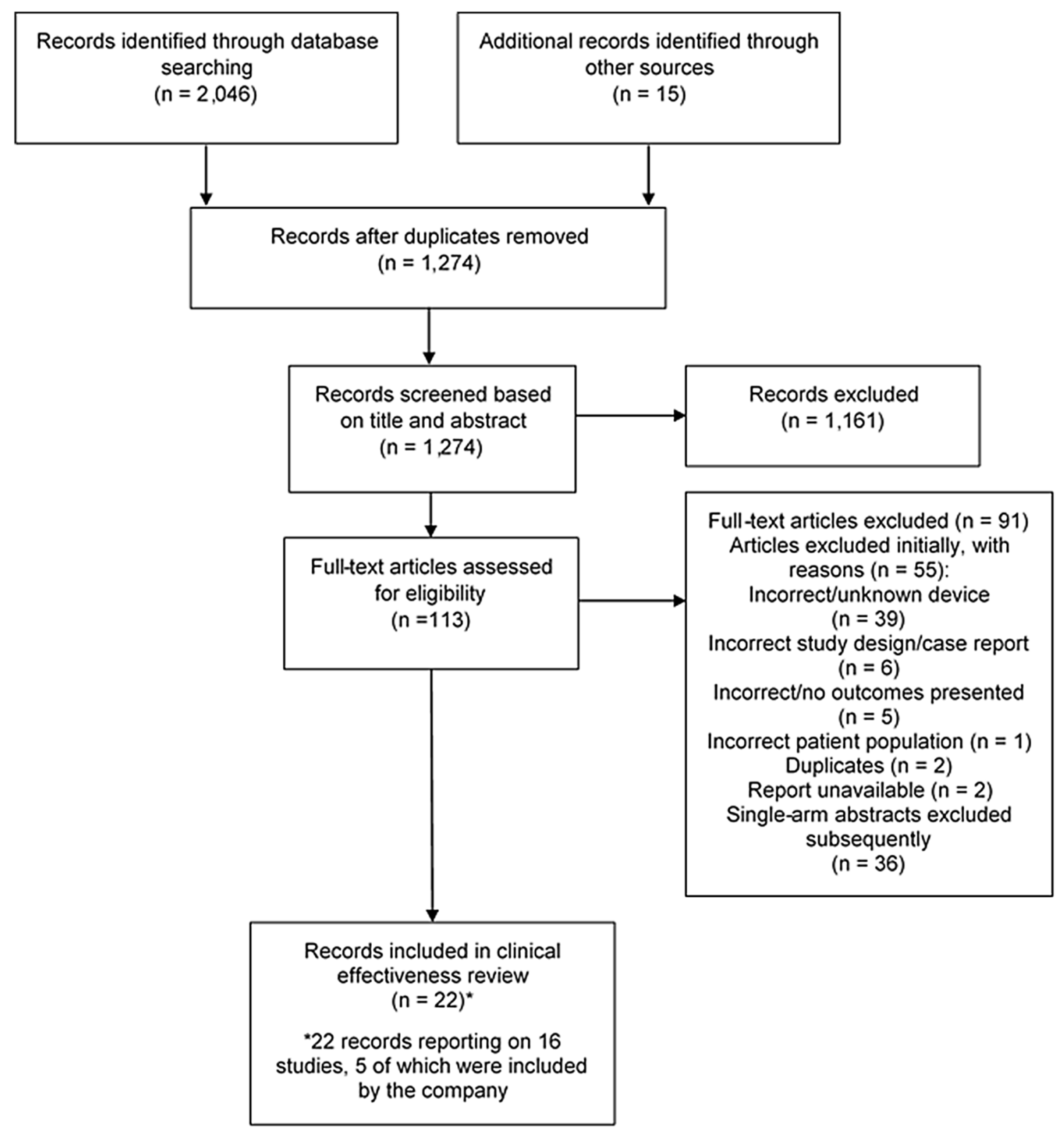

Fig. 1 EAC's PRISMA diagram. EAC External Assessment Centre

The EAC identified significant limitations across the methodology and results of the company's review of the clinical evidence. The company included only six publications [2, 19-23], which reported on five studies, whilst the EAC identified 22 publications [7, 16, 19-21, 24-34], which reported on 16 studies, through its de novo searches. Overall, the entirety of the low-quality evidence suggests Memokath-051 has similar success rates compared with double-J stents and Resonance stents, but worse outcomes than the other devices. The most commonly reported adverse event associated with Memokath-051 was stent migration, which occurred more frequently in Memokath051 than in any of the comparators assessed.

\subsection{Economic Evidence}

\subsubsection{Company's Economic Submission}

The company conducted a limited search for economic evidence, and of the 54 unique records identified, three studies were included in the company's economic review [20, 22, 35]. Each compared Memokath-051 with double-J stents, but no results were reported by the company. The EAC judged one study to be poorly conducted and reported [36] and the second difficult to appraise because it was published as an abstract only [37]. The final study was an unpublished cost-minimisation analysis reported by an 


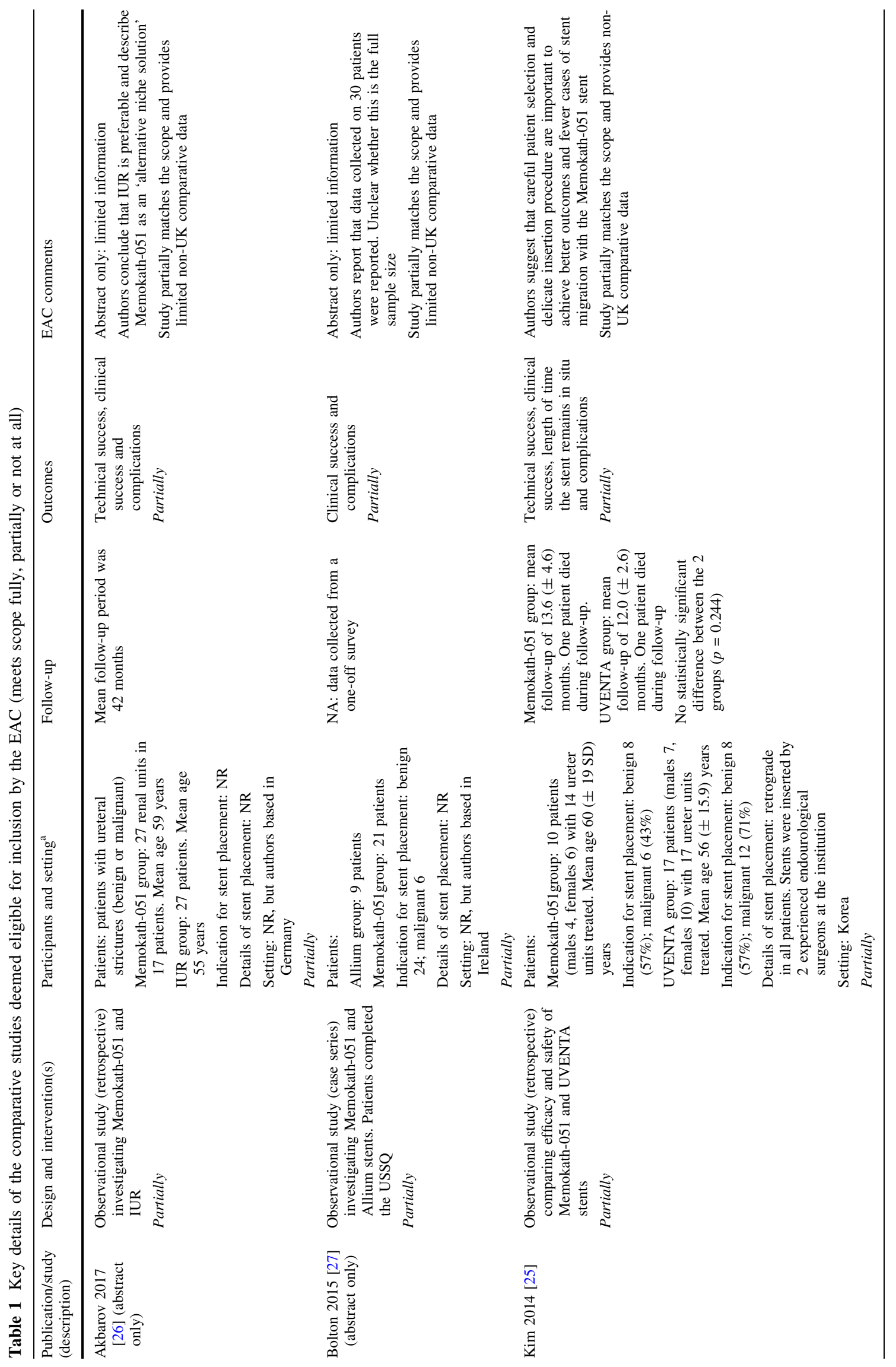




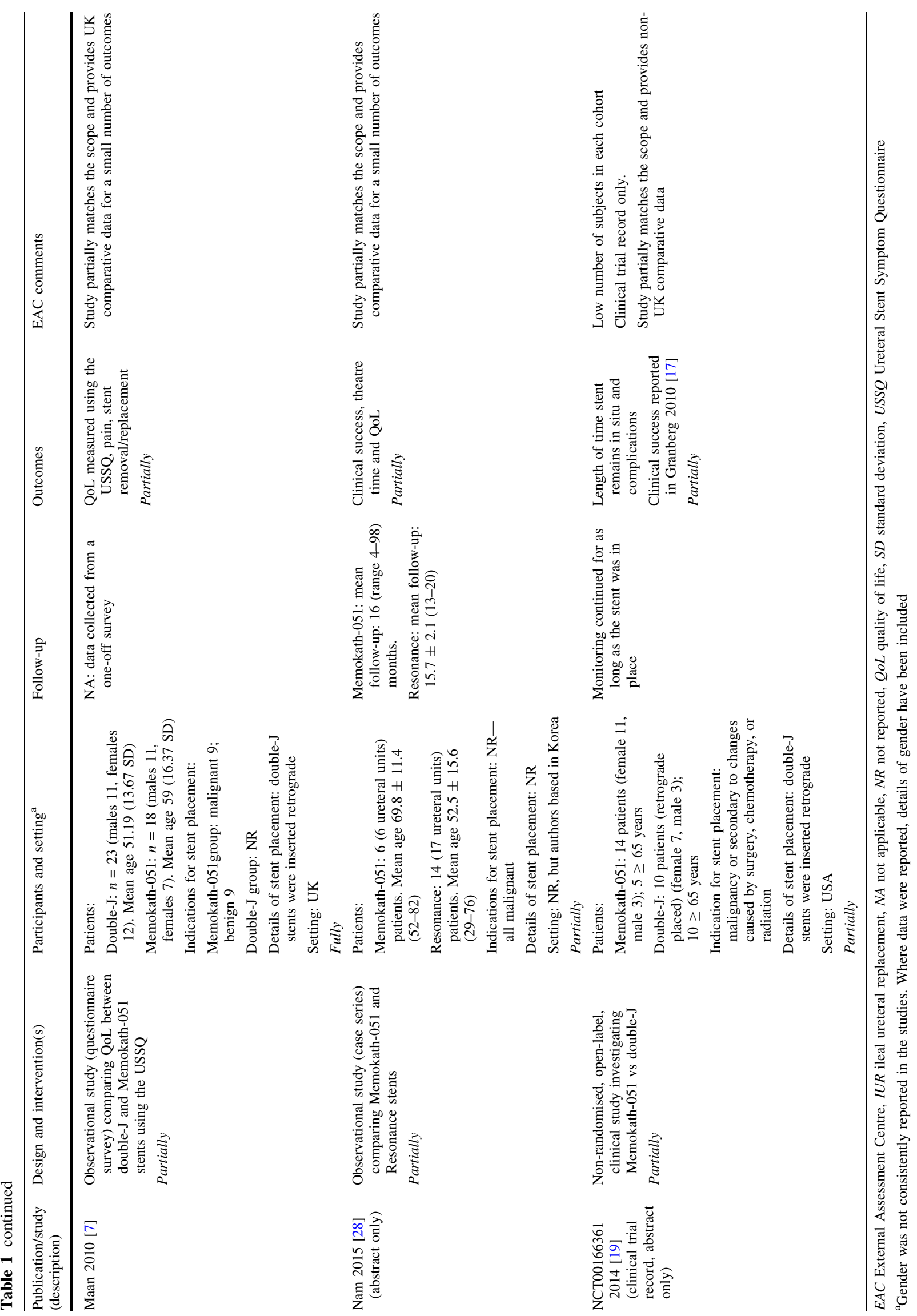




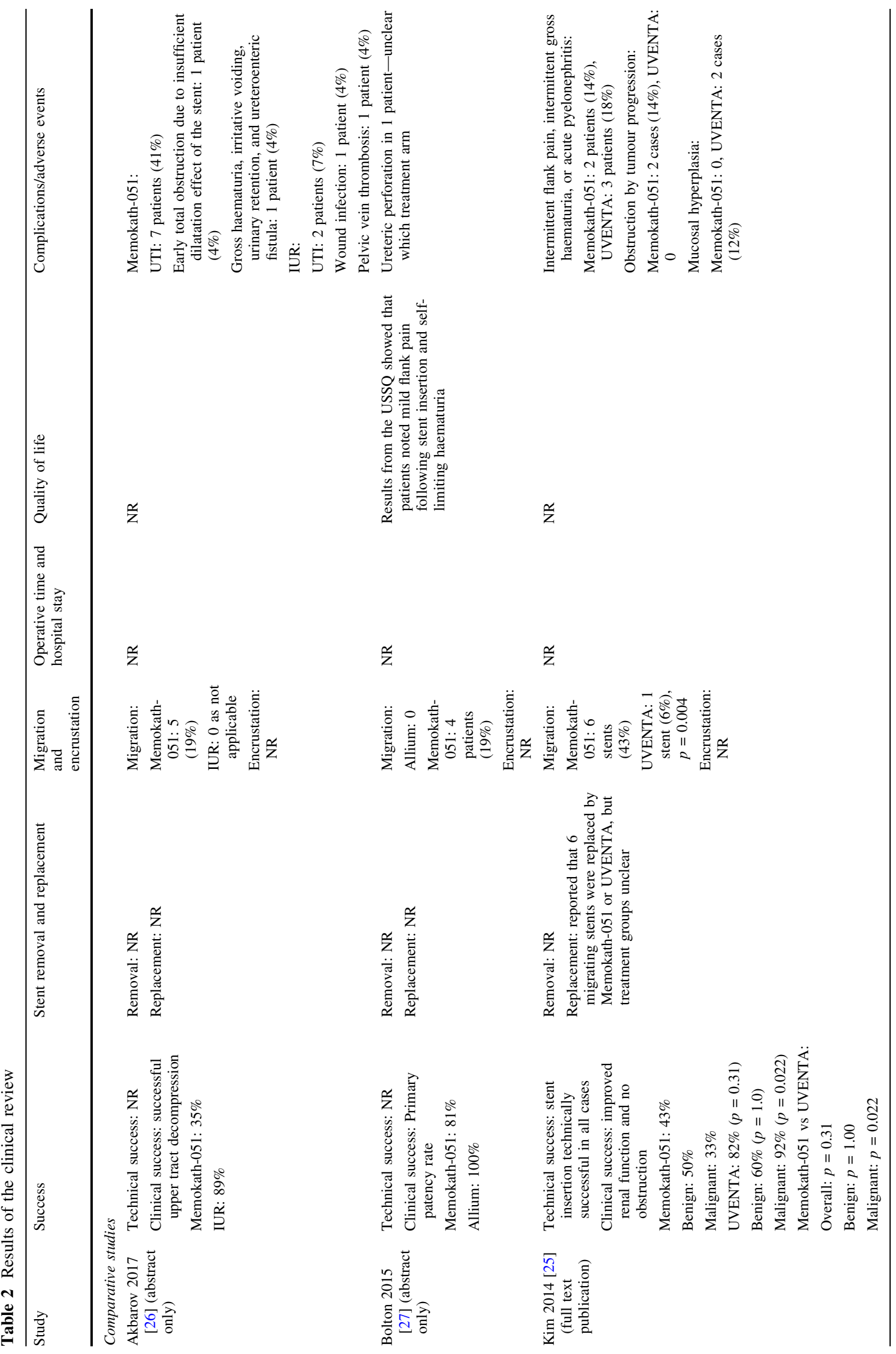




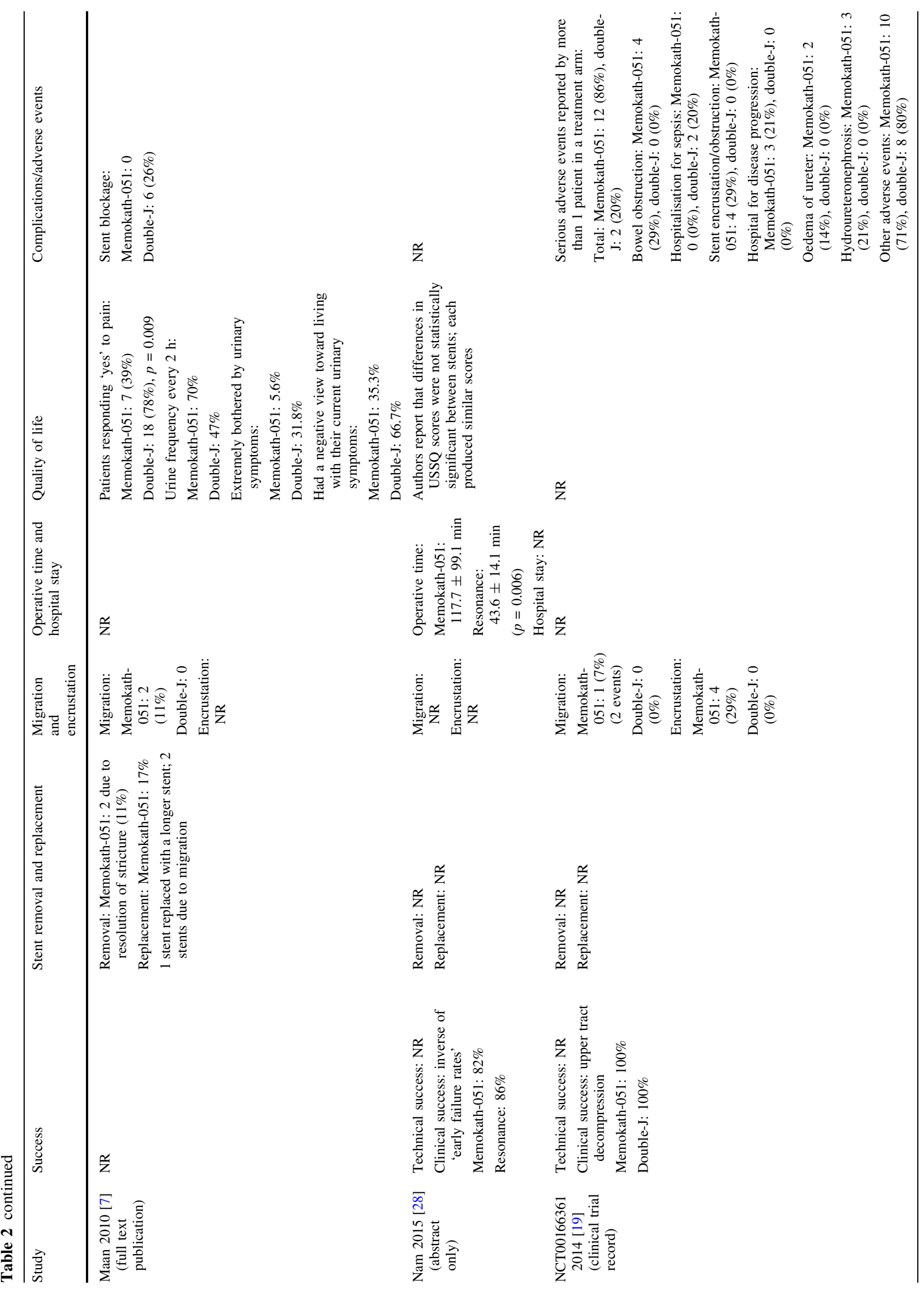




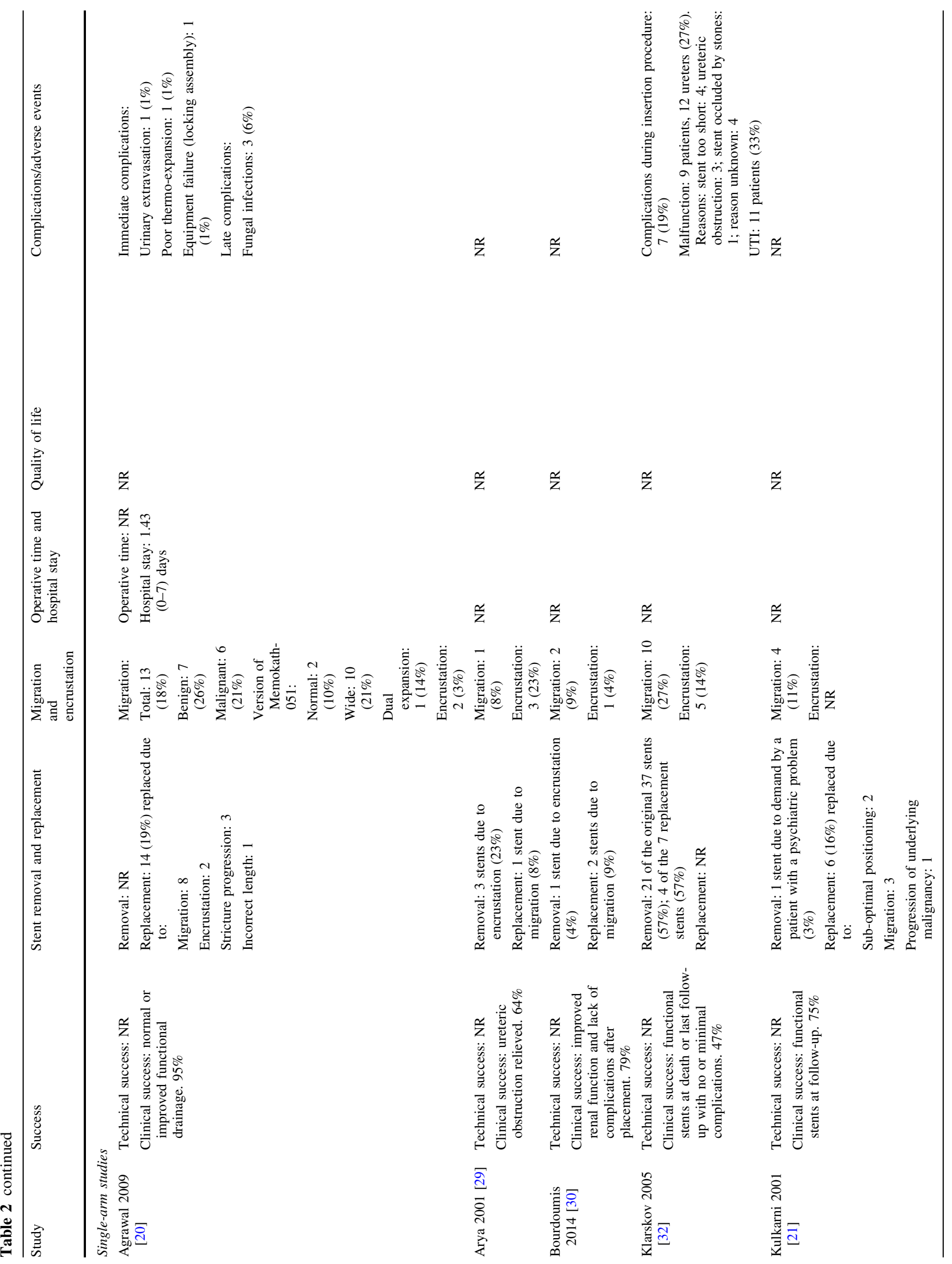




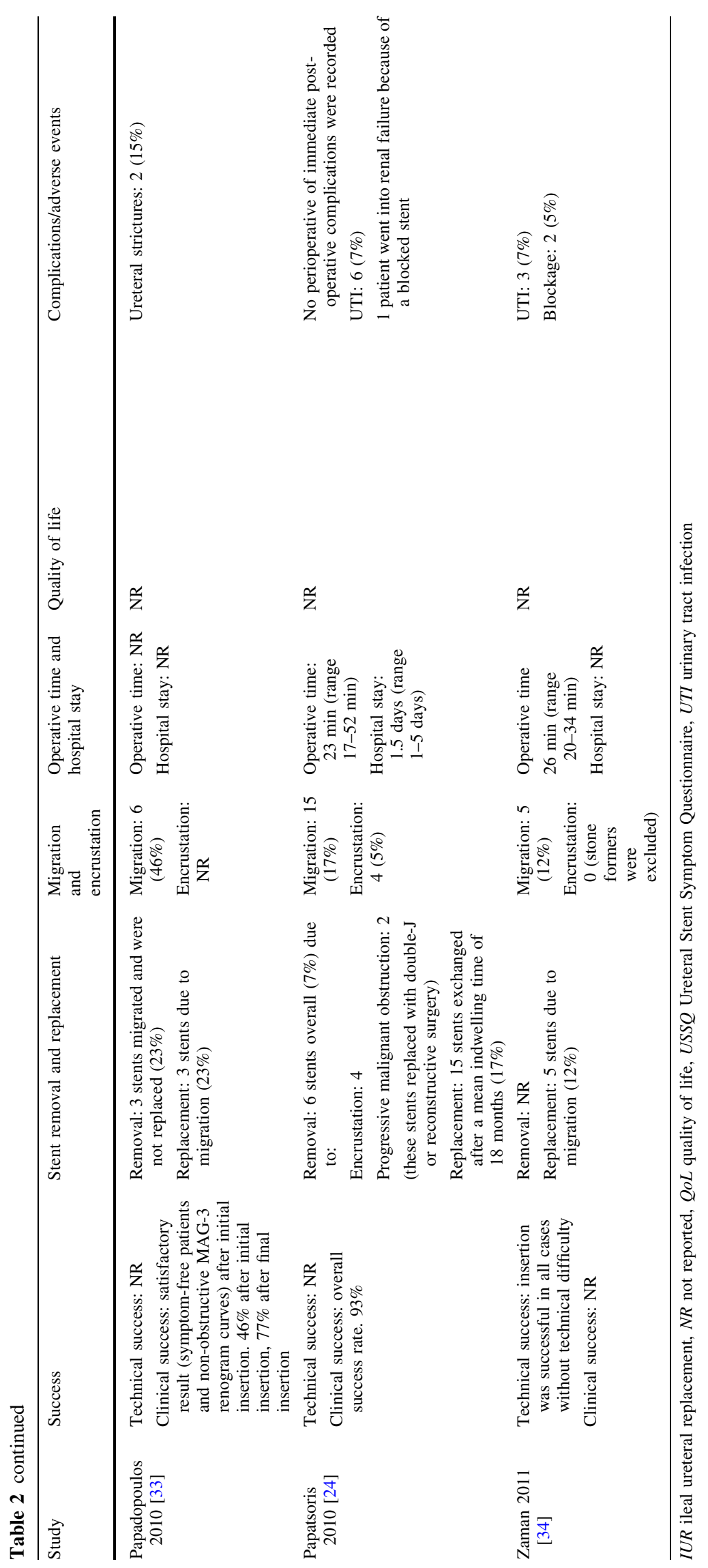


English NHS hospital (Aintree University Hospital) and thus was also difficult to appraise [35]. The company used data from this study within its submission.

The company submitted a de novo cost model (or cost calculator), comparing Memokath-051 with double-J stents over a time horizon of 2.5 years, developed in Microsoft Excel $^{\circledR}$. For both technologies, the cost of insertion (including the cost of theatre staff, consumables and the theatre tariff) and the cost of follow-up visits were included. Complications associated with the device were only included in the Memokath-051 arm and were encapsulated within a risk factor for an unplanned stent exchange. This was applied by multiplying the sum of the pathway-related costs per patient over the 2.5 -year time horizon by $25 \%$. This cost premium was added to the total cost over 2.5 years for treatment with Memokath-051. The Memokath-051 stent did not have a planned replacement within the 2.5-year time horizon. Replacement of double-J stents occurred every 6 months and so the cost of the initial double-J stent insertion and four planned stent exchanges, as well as the patient follow-up appointments, were summed to generate the total per patient cost over 2.5 years for double-J stents. Figure 2 is a diagram of the company's model (developed by the EAC).

To populate its economic analysis, the company primarily utilised data from a cost-minimisation analysis conducted by Aintree University Hospital [35]. This reported on the costs associated with the use of Memokath051 compared with double-J stents for 24 patients requiring 32 stents for long-term stenting of malignant and benign strictures. The risk factor for an unplanned stent exchange in the Memokath-051 arm was justified by the company with reference to a clinical study [24], but a clear explanation of where this value was derived from was not provided. The perspective adopted was not reported by the company, but given that all costs modelled were sourced from a single English hospital, an NHS hospital perspective was taken. All model input parameters are shown in Table 3. Further details are given in the EAC report [5].

Base case results from the company's model estimated that Memokath-051 generated cost savings of $£ 4156$ per patient compared with double-J stents. This was based on costs of $£ 4726$ per patient treated with Memokath-051 and $£ 8882$ per patient receiving double-J stent. No sensitivity or subgroup analyses were conducted by the company.

\subsubsection{Critique of Economic Evidence}

The EAC did not evaluate or re-run the company's economic searches given the limited description of the search, but conducted its own literature search. The EAC judged two of the company's included studies to be out of scope $[20,22]$, but agreed that inclusion of the cost-minimisation analysis [35] was appropriate. Two further studies were included by the EAC $[36,37]$. All three included studies were cost-consequence analyses comparing Memokath-051 with double-J stents, with only the analysis conducted by Aintree University Hospital representative of NHS practice [35]. This reported cost savings of $£ 27$ in the first year and $£ 4095$ in the second year when using Memokath-051 compared to double-J stents.

The EAC judged it appropriate for the company to develop its own de novo cost model given the limited published evidence. Whilst the model captured the key differences between the two stent types, namely the cost of insertion, planned replacements with double-J stents and unplanned replacements with Memokath-051, the model was not executable, reported results based on an unpublished analysis [35], and took a hospital perspective. This deviates from the scope, which requires that an NHS and Personal Social Services (PSS) perspective is taken. Further, the EAC identified that data were available for other metallic stents and surgical procedures used within the NHS, enabling cost comparisons with Memokath-051 to be undertaken. However, there were insufficient data on nephrostomy.

The EAC replicated the company's calculations and identified no calculation errors. The Drummond checklist was used to appraise the model [38], identifying the following issues:

- A time horizon of 2.5 years was used, but limited data were reported in the comparative trials in relation to the length of time in situ, and these data were driven by the follow-up of the trials.

- The model assumes that all patients remain alive at 2.5 years following insertion, which may not be the case for patients with shorter life expectancy.

- Adverse events that do not result in the removal of the stent, such as urinary tract infection (UTI), were excluded. The clinical review identified that some patients experienced these adverse events after stenting [19, 26, 32, 34].

- The company's model did not capture benefits relating to reduced pain and improved quality of life with Memokath-051 [7].

- Discounting was not applied to costs that occur beyond year 1 , as required by NICE [39].

- Sensitivity analyses were omitted.

All model inputs used by the company were validated by the EAC, with some issues identified. A key clinical parameter used by the company in the Memokath-051 arm was to assume $25 \%$ of patients require a stent replacement over 2.5 years (equivalent to $0.89 \%$ per month). This value was not supported by the clinical evidence, where a value of $1.4 \%$ per month was estimated 


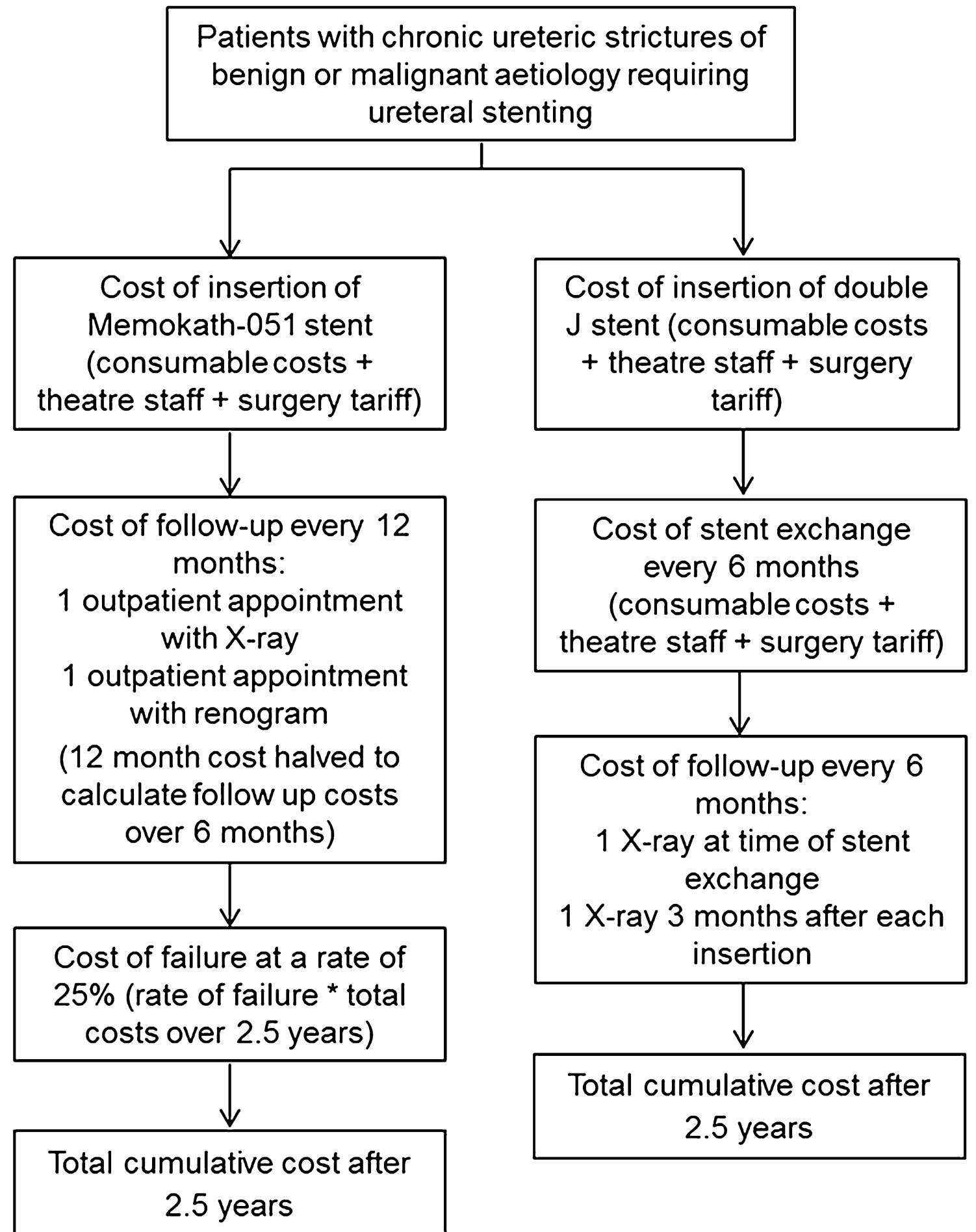

Fig. 2 Economic model schematic developed by the company. Asterisk refers to multipled by

[20, 21, 24, 25, 29, 30, 33]. Regarding resource use, whilst expert advice verified that the composition of theatre staff included was appropriate, the procedure time for insertion and replacement surgeries was overestimated at $4 \mathrm{~h}$. Procedure times for the insertion of Memokath-051 and double-J stents of 45 and $22.5 \mathrm{~min}$, respectively, were deemed more appropriate by the EAC based on expert advice. Theatre staff costs were also included as salary costs, hence inappropriately omitting other salary-related costs (national insurance and superannuation). The company also included a surgery tariff in their model, which was inappropriate given the perspective adopted. The amendments to the 
Table 3 Model input parameters used in company's model

\begin{tabular}{|c|c|c|c|}
\hline Variable & $\begin{array}{l}\text { Value } \\
\text { per } \\
\text { patient }\end{array}$ & Source & EAC critique \\
\hline $\begin{array}{l}\text { Theatre staff } \\
\text { costs: } \\
\text { Memokath-051 }\end{array}$ & $£ 1160$ & $\begin{array}{l}\text { [35] } \\
\text { Included: anaesthetist, surgeon, band } 6 \text { and band } 5 \\
\text { scrub, band } 5 \text { anaesthetist, band } 2 \text { circulating, band } 2 \\
\text { porter, band } 6 \text { and band } 5 \text { recovery }\end{array}$ & $\begin{array}{l}\text { Duration of procedure: procedure time of } 4 \mathrm{~h} \text { and a } \\
\text { theatre time (all staff present apart from the surgeon) } \\
\text { of } 4.5 \mathrm{~h} \text {. The EAC judged this to be too long based } \\
\text { upon information provided by the company and } \\
\text { experts } \\
\text { Recovery staff: Cost of a band } 5 \text { and band } 6 \text { recovery } \\
\text { staff included appropriately given that no additional } \\
\text { hospital stay was included following insertion } \\
\text { Staff costs: Staff costs per hour did not include national } \\
\text { insurance and superannuation costs. These are directly } \\
\text { related to earnings and should be included }\end{array}$ \\
\hline $\begin{array}{l}\text { Theatre staff } \\
\text { costs: double-J } \\
\text { stent }\end{array}$ & $£ 1160$ & $\begin{array}{l}\text { [35] } \\
\text { Included: anaesthetist, surgeon, band } 6 \text { and band } 5 \\
\text { scrub, band } 5 \text { anaesthetist, band } 2 \text { circulating, band } 2 \\
\text { porter, band } 6 \text { and band } 5 \text { recovery }\end{array}$ & $\begin{array}{l}\text { Duration of procedure: as above } \\
\text { Recovery staff: as above } \\
\text { Staff costs: as above }\end{array}$ \\
\hline $\begin{array}{l}\text { Theatre } \\
\text { consumable } \\
\text { costs: } \\
\text { Memokath-051 }\end{array}$ & $£ 1874$ & $\begin{array}{l}\text { I35] } \\
\text { Included: device, cystoscopy pack, instilagel, 20-ml } \\
\text { syringe, sensor guide wire, passport, jug, pink needle, } \\
\text { green needle }\end{array}$ & $\begin{array}{l}\text { The company’s consumable cost includes a device cost } \\
\text { of } £ 1630 \text {. This is lower than the current list price of } \\
£ 1690 \text { reported in the company’s submission }\end{array}$ \\
\hline $\begin{array}{l}\text { Theatre } \\
\text { consumable } \\
\text { costs: double-J } \\
\text { stent }\end{array}$ & $£ 109$ & $\begin{array}{l}\text { [35] } \\
\text { Included: device, cystoscopy pack, instilagel, 20-ml } \\
\text { syringe, sensor guide wire }\end{array}$ & $\begin{array}{l}\text { The EAC deems this value appropriate based upon the } \\
\text { AUH data [35] }\end{array}$ \\
\hline $\begin{array}{l}\text { Procedure } \\
\text { code/surgery } \\
\text { tariff: } \\
\text { Memokath- } 051\end{array}$ & $£ 34$ & {$[35]$} & $\begin{array}{l}\text { The EAC judges the inclusion of a tariff cost is } \\
\text { inappropriate for analysis from the NHS and PSS } \\
\text { perspective and excluded this parameter from its } \\
\text { analysis }\end{array}$ \\
\hline $\begin{array}{l}\text { Procedure } \\
\text { code/surgery } \\
\text { tariff: double-J } \\
\text { stent }\end{array}$ & $£ 407$ & {$[35]$} & As above \\
\hline $\begin{array}{l}\text { 6-month follow- } \\
\text { up costs: } \\
\text { Memokath-051 }\end{array}$ & $£ 143$ & $\begin{array}{l}\text { I35] } \\
\text { Included: x-ray abdomen, nuclear medicine renogram } \\
\text { and } 2 \text { outpatient appointments over } 1 \text { year. } 1 \text { year cost } \\
\text { divided by } 2 \text { to estimate the } 6 \text { month cost }\end{array}$ & $\begin{array}{l}\text { The EAC deems this value appropriate based upon the } \\
\text { AUH data. However, using national sources for unit } \\
\text { costs would increase the cost }[40]\end{array}$ \\
\hline $\begin{array}{l}\text { 6-month follow- } \\
\text { up costs: } \\
\text { double-J stent }\end{array}$ & $£ 100$ & No source provided & $\begin{array}{l}\text { It is unclear how this cost was derived and is not } \\
\text { included within the AUH data, thus is deemed } \\
\text { inappropriate }\end{array}$ \\
\hline $\begin{array}{l}\text { Risk of unplanned } \\
\text { exchange: } \\
\text { Memokath- } 051\end{array}$ & $£ 945$ & $\begin{array}{l}\text { Calculated as } 25 \% \text { of the undiscounted pathway-related } \\
\text { cost for } 2.5 \text { years }\end{array}$ & $\begin{array}{l}\text { The EAC judges that this cost has been applied } \\
\text { incorrectly given that it was applied to the total per } \\
\text { patient cost over } 2.5 \text { years as opposed to the insertion } \\
\text { cost only }\end{array}$ \\
\hline $\begin{array}{l}\text { Risk of unplanned } \\
\text { exchange: } \\
\text { double-J stent }\end{array}$ & $£ 0$ & Zero as no risk factor for complications & $\begin{array}{l}\text { Given that double-J stents undergo planned } \\
\text { replacement, this is considered appropriate and is in } \\
\text { line with clinical evidence [7] }\end{array}$ \\
\hline
\end{tabular}

AUH Aintree University Hospital, EAC External Assessment Centre, NHS National Health Service, PSS Personal Social Services

company's input values resulted in the EAC using a total cost of insertion for Memokath-051 of $£ 3010$ instead of the company's value of $£ 3068$ and a cost of $£ 786$ for double-J stents as opposed to the company's estimate of $£ 1676$.

\subsubsection{Additional Work Undertaken by EAC Relating to Economic Evidence}

Given the limitations described in Sect. 4.2.2, the EAC adapted the company's model. The patients and 


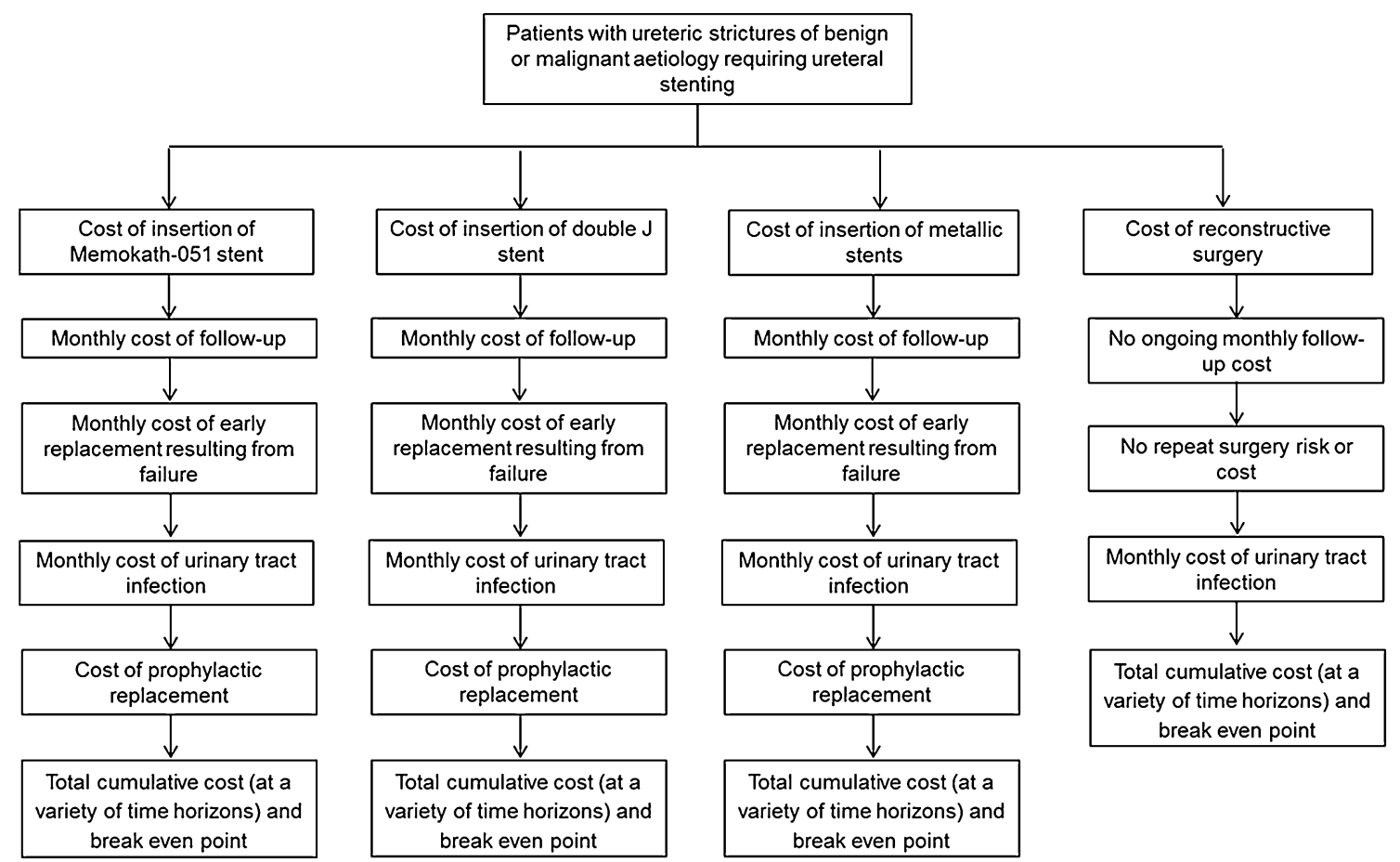

Fig. 3 Economic model schematic developed by the EAC. EAC External Assessment Centre

interventions included in the EAC's model were aligned with the scope, except the exclusion of nephrostomy as a comparator. Costs were modelled over a 5-year time frame, reflecting the indwelling duration for Memokath-051, after which planned replacement is required according to the company. The EAC's model was updated such that time was explicitly modelled by month, allowing the break-even point between Memokath-051 and its comparators to be determined. However, the assumption of patients surviving for the duration of the model was retained.

To determine the pathway costs with Memokath-051, double-J stents and other metallic stents, the EAC included the costs of:

- Initial insertion for all patients (including the costs of the device, consumables, staff, theatre and immediate follow-up).

- On-going follow-up for all patients.

- Unplanned replacement costs where necessitated by an adverse event (including the cost of consumables, staff, theatre and follow-up).

- UTI costs for those experiencing a UTI (general practitioner visit and antibiotics).

- Planned replacement for all patients based upon the instructions for use for each comparator device.

Given that the monthly risk of unplanned replacements was derived from the clinical studies and that the follow-up of these studies was shorter than the time horizon of the model, extrapolation was required. Three extrapolation methods were considered: (1) a uniform monthly risk of unplanned replacement was applied for the 5-year horizon of the model; (2) the monthly risk of unplanned replacement was applied for 2 years followed by no risk of unplanned replacement; (3) the monthly risk of unplanned replacement was applied for 2 years followed by a reduced risk of unplanned replacement. The latter two scenarios attempted to capture scenarios in which unplanned replacements occur early in a stent's lifespan, rather than spontaneously occurring after the stent has been in situ with no complications for 2 years.

The pathway associated with reconstructive surgery (conservatively assumed to be successful in all cases) was costed. Whilst some patients may require additional surgery, the magnitude of this could not be identified from either the literature or the experts and so was not modelled. All patients were assumed to require follow-up in the first month post-surgery. Experts advised that most patients would not have continued follow-up thereafter. Figure 3 gives a schematic of the EAC's model.

Table 4 summarises the model inputs included by the EAC.

The EAC generated results based on various scenarios relating to unplanned stent replacement for all stents. In all scenarios, Memokath-051 was cost saving compared with double-J stents within a 5-year time horizon. The breakeven point between Memokath-051 and double-J stents was 30 months in all scenarios. Memokath-051 improved patient-related quality of life compared with double-J 


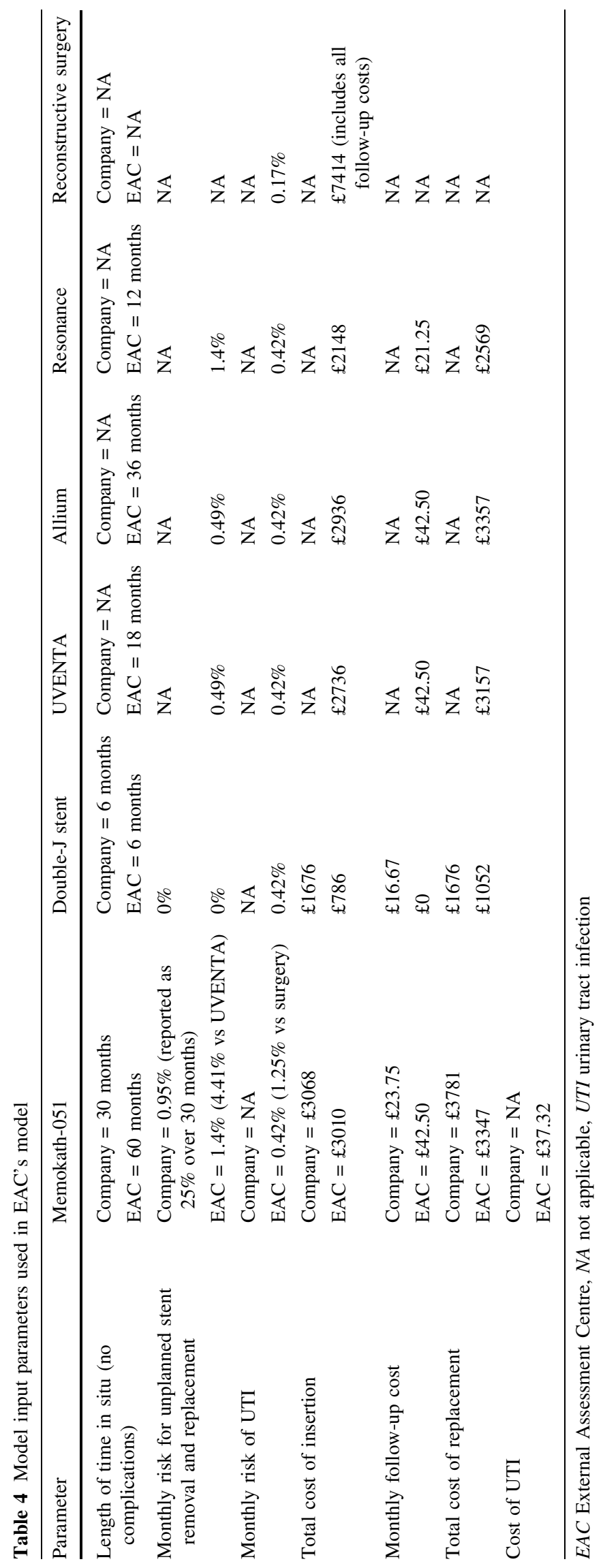


stents. The EAC's estimated savings per patient with Memokath-051 ranged from $£ 1619$ to $£ 3095$, depending on the scenario, somewhat lower than the company's estimate (£4156).

When comparing Memokath-051 to reconstructive surgery, the incremental cost per patient after 5 years ranged from $£ 467$ to $-£ 1009$, depending upon the assumptions made around the extrapolation of unplanned replacement of Memokath-051 stents. Compared with surgery, Memokath-051 was cost saving up to 53 months, suggesting that if costs are the only criterion then Memokath-051 is the optimal choice for patients with a lower life expectancy. Reconstructive surgery would be the preferred option for patients able to tolerate it and anticipated to live longer than 4.5 years.

The key factor in comparisons between Memokath-051 and other metallic stents is the planned stent replacement for each comparator. Based on the EAC's analysis, Memokath-051 is judged to be cost neutral compared with UVENTA and Allium in the worst case (i.e. uniform rate of replacement), but may generate cost savings with more positive assumptions (i.e. no unplanned replacements after 2 years). Compared with Resonance, Memokath-051 was cost saving after 12 months. The results for both Allium and Resonance should be interpreted with caution as they are based on assumptions and not comparative clinical data.

The EAC identified a plausible range for each input parameter and varied the parameter within this range. When comparing Memokath-051 to double-J stents, for the scenario with a constant risk of unplanned replacement over 5 years (most conservative scenario), the results were sensitive to the procedure costs of replacing double-J stents and the risk of unplanned replacements with Memokath051. Where the replacement procedure cost for double-J stents was below $£ 860$ (consistent with a procedure time of $38 \mathrm{~min}$ or less) or the monthly risk of unplanned replacements with Memokath-051 was above $3.6 \%$ per month, Memokath-051 was cost incurring. A monthly risk of replacement of above $4 \%$ was only reported in one non-UK study [25], whilst the remaining studies reported monthly risks of replacement of $1.6 \%$ or below. In all univariate analyses, break-even occurred by month 42 , except for those analyses varying the procedure costs of replacing double-J stents and the risk of unplanned replacements with Memokath-051.

Compared with the other metallic stents, results were most sensitive to the risk of unplanned replacement with Memokath-051 stents. Model results were highly sensitive to many input values when Memokath-051 was compared with surgery, particularly in the worst-case scenario.

\section{NICE Guidance}

\subsection{Provisional Recommendations}

The evidence submitted by the company and the EAC's critique of this evidence was presented to the MTAC, who provided draft recommendations relating to Memokath-051 following their meeting in September 2017. These are summarised as follows:

- The case for adopting Memokath-051 stents for the treatment of ureteric obstruction is partially supported by the evidence. There is limited clinical, procedural and outcomes evidence, and clinicians using ureteric stents including Memokath-051 stents should therefore submit data to a national registry.

- Memokath-051 stents, when implanted by trained and experienced surgeons and in appropriate patients, are associated with equivalent success rates to double-J stents and a better patient experience.

- The cost consequences of adopting the Memokath-051 stent in current pathways are uncertain. However, when used in specific populations and by experts trained in its use, it may be cost neutral or cost saving compared with standard treatment because of reduced need for repeat procedures.

\subsection{Consultation Response}

During the consultation, NICE received 19 consultation comments from seven consultees. The NICE guidance was updated to address a number of these comments. The recommendations were updated in response to a comment regarding a national registry and to provide clarification on patient choice. Although the committee considered that data collection was still needed to better understand the benefits of Memokath-051, it decided to remove a specific recommendation about the type of data collection to allow for further discussion. Further changes were made to better reflect that patients may choose to decline particular treatments. These changes were augmented with additional explanatory text in the patient selection with benign ureteric obstruction and future data collection sections.

\section{Key Challenges and Learning Points}

There were some key challenges faced by both the EAC and the company during the evaluation. The analysis was not able to fully address the decision problem given that data on nephrostomy and all of the subgroups defined in the scope were not available. The available evidence base 
comprised mainly small, poorly reported, observational studies. Although the observational nature of the studies may be more reflective of real life, due to the heterogeneity across them it is difficult to draw reliable conclusions. The poor quality of data increased reliance on expert advice thus increasing the demands of the project given the specified timelines. Further, there were multiple comparators included in the scope, which increased the demand for data. The comparative evidence for Memokath-051 versus Resonance and Allium stents was poor, meaning that there is even greater uncertainty around the results. Therefore, all conclusions are uncertain and could alter with new evidence. A large, well conducted randomised controlled trial or prospective comparative study would improve the evidence base and provide more reliable estimates of the efficacy and safety of these devices.

There were also multiple types of reconstructive surgery available to these patients, which were not modelled explicitly. The inclusion of reconstructive surgery as a comparator treatment has some caveats associated with it as highlighted by the clinical experts. The major caveat is that reconstructive surgery aims to be curative; thus it should always be considered for patients with a longer life expectancy who are able to tolerate major surgery.

It was clear during the analysis that the patient population was heterogeneous, with the patient's life expectancy being an important factor. To account for this, the EAC identified the break-even point as the month up to which Memokath-051 would generate cost savings for each comparative analysis.

An additional challenge for this analysis was the uncertainty associated with the maximum duration of stent indwelling. This issue arose given that the length of the follow-up period of the clinical trials was shorter than the indicated lifetime for stent replacement. The EAC used four methods of extrapolation to account for different possible scenarios. When generating the results for Memokath-051 compared with each comparator, there was no clear base case and instead the results were reported for each of the different scenarios.

Lastly, a particular challenge faced by the EAC was the poor quality of the company's submission. This resulted in a significant amount of additional work being conducted by the EAC. NICE can offer assistance to companies prior to the assessment process, and utilisation of this by the company could have led to a more efficient assessment of the device.

\section{Conclusion}

The MTEP evaluation process was followed for the development of medical technologies guidance on Memokath-051. This included a submission of clinical and economic evidence by the company, critical appraisal of this evidence by the EAC, extensive additional work by the EAC to capture all available evidence relating to the decision problem and to develop an executable economic model to help inform the decision makers' recommendations and capture the uncertainty of the decision, drafting of recommendations by the MTAC, and a subsequent public consultation. Following this process, the MTAC judged that the evidence demonstrated sufficient potential benefits of Memokath-051 to patients and the NHS to allow partially supportive recommendations to be made for the device.

Acknowledgements The authors are grateful to the clinical experts identified by NICE, who provided expertise and clinical knowledge.

Author Contributions The manuscript was prepared by EET, with contributions from MJ, RM, CM, LM, HW, AP, JC and AS. Literature searching was undertaken by $\mathrm{HW}$ and evidence review by RM and $\mathrm{CM}$, with advice and quality assurance from JC and AS. The model critique was undertaken by EET, AP and $\mathrm{MJ}$, with advice and quality assurance from JC and AS. LM reported the decision problem and the NICE recommendations. The guarantor for overall content is AS.

\section{Compliance with Ethical Standards}

Funding Newcastle upon Tyne Hospitals and York Health Economics Consortium are funded by NICE to act as an EAC for the Medical Technologies Evaluation Programme.

Conflict of interest This summary of the Medical Technology Guidance was produced following publication of the final guidance report. This summary has not been externally peer reviewed by $A p$ plied Health Economics and Health Policy.One of the authors (AS) is an NHS employee; the NHS has a financial interest in the guidance issued by NICE as a result of this work. Seven of the authors (MJ, EET, CM, RM, AP, HW and JC) work for the EAC, but otherwise have no conflicts of interest. LM is an employee of NICE.

Open Access This article is distributed under the terms of the Creative Commons Attribution-NonCommercial 4.0 International License (http://creativecommons.org/licenses/by-nc/4.0/), which permits any noncommercial use, distribution, and reproduction in any medium, provided you give appropriate credit to the original author(s) and the source, provide a link to the Creative Commons license, and indicate if changes were made.

\section{References}

1. Campbell B, Campbell M. NICE medical technologies guidance: a novel and rigorous methodology to address a new health technology assessment challenge. Appl Health Econ Health Policy. 2012;10(5):295-7.

2. Kulkarni RP, Bellamy EA. A new thermo-expandable shapememory nickel-titanium alloy stent for the management of ureteric strictures. BJU Int. 1999;83(7):755-9.

3. National Institute for Health and Care Excellence (NICE). Medical technologies evaluation programme process guide. London: NICE; 2017. 
4. Eaton Turner E, Jenks M, Marshall C, McCool R, Wood H, Peel A et al. The Memokath-051 stent for the treatment of ureteric obstruction (assessment report). 2017.

5. National Institute for Health and Care Excellence. Memokath051 stent for ureteral obstruction. 2017. https://www.nice.org.uk/ guidance/indevelopment/gid-mt512.

6. NHS North Bristol Trust. Having a ureteric stent: what to expect and how to manage. 2014. https://www.nbt.nhs.uk/sites/default/ files/attachments/Having\%20a\%20Ureteric\%20Stent_ NBT002639.pdf. Accessed 10th May 2017.

7. Maan Z, Patel D, Moraitis K, El-Husseiny T, Papatsoris AG, Buchholz N-P, et al. Comparison of stent-related symptoms between conventional double-J stents and a new-generation thermoexpandable segmental metallic stent: a validated-questionnaire-based study. J Endourol. 2010;24(4):589-93. https:// doi.org/10.1089/end.2009.0318.

8. Abdallah MM, Selim M, Abdelbakey T. Thermo-expandable metallic urethral stents for managing recurrent bulbar urethral strictures: to use or not? Arab J Urol. 2013;11(1):85-90. https:// doi.org/10.1016/j.aju.2012.12.005.

9. National Institute for Health and Care Excellence. Memokath051 stent for ureteral obstruction: final scope. 2017. https://www. nice.org.uk/guidance/indevelopment/gid-mt512/documents.

10. Chow P-M, Chiang IN, Chen C-Y, Huang K-H, Hsu J-S, Wang $\mathrm{S}-\mathrm{M}$, et al. Malignant ureteral obstruction: functional duration of metallic versus polymeric ureteral stents. PLoS One. 2015;10(8):e0135566. https://doi.org/10.1371/journal.pone. 0135566.

11. Pavlovic K, Lange D, Chew B. Stents for malignant ureteral obstruction. Asian Journal of Urology. 2016;3(3):142-9.

12. Health and Social Care Information Centre. Hospital Episode Statistics, Admitted Patient Care - England, 2014-15: Procedures and interventions: 4 character. 2015. http://content.digital.nhs.uk/ catalogue/PUB19124. Accessed 11 May 2017.

13. Cook Medical. Resonance metallic ureteral stent set: instructions for use. United States: Cook Medical. 2012. https://www. cookmedical.com/data/IFU_PDF/IFU0020-14.PDF. Accessed 11 May 2017.

14. National Institute for Health and Care Excellence. Briefing note for the selection and routing of: theMemokath-051 stent for ureteral obstruction; 2017 (unpublished).

15. Allium Medical. Allium ureteral stent (URS): instructions for use. Kingdom: Allium. 2016. http://www.alliummedical.com/uploads/ images/IFU\%20for\%20URS-243-0217-Brochure.pdf. Accessed 11 May 2017.

16. Bach C, Kabir MN, Goyal A, Malliwal R, Kachrilas S, El Howairis ME, et al. A self-expanding thermolabile nitinol stent as a minimally invasive treatment alternative for ureteral strictures in renal transplant patients. J Endourol. 2013;27(12):1543-5. https://doi.org/10.1089/end.2013.0180.

17. Granberg C, Russell S, Siddiqui S, Nehra A, Frie K, Leroy A, et al. Long term drainage of malignant extrinsic ureteral obstruction secondary to inoperable pelvic or abdominal malignancies using the Memokath 051 ureteral stent. J Urol. 2010;1:e495. https://doi.org/10.1016/j.juro.2010.02.850.

18. NHS Supply Chain. 2017. https://my.supplychain.nhs.uk/ catalogue/search?query=double-J\%20stent. Accessed 11 May 2017.

19. Mayo Clinic. Drainage of malignant extrinsic ureteral obstruction using the Memokath ureteral stent. Identifier: NCT00166361. In: ClinicalTrials.gov. Bethesda. US National Library of Medicine. 2014. Available from: https://clinicaltrials.gov/ct2/show/ NCT00166361.

20. Agrawal S, Brown CT, Bellamy EA, Kulkarni R. The thermoexpandable metallic ureteric stent: an 11-year follow-up. BJU Int.
2009;103(3):372-6. https://doi.org/10.1111/j.1464-410X.2008. 08018.x.

21. Kulkarni R, Bellamy E. Nickel-titanium shape memory alloy Memokath 051 ureteral stent for managing long-term ureteral obstruction: 4-year experience. J Urol. 2001;166(5):1750-4.

22. Papatsoris A, Masood J, El-Husseiny T, Ndirika S, Buchholz N. A novel long-term thermo-expandable ureteric metal stent: Memokath 051. BJU Int. 2007;21:1-10.

23. Patel D, Maan Z, El-Husseiny T, Moraitis K, Junaid I, Buchholz $\mathrm{N}$, et al. Characterising stent symptoms associated with a segmental thermo-expandable metallic stent using a validated stent symptoms questionnaire. Curr Urol. 2011;5(2):72-8. https://doi. org/10.1159/000327454.

24. Papatsoris AG, Buchholz N. A novel thermo-expandable ureteral metal stent for the minimally invasive management of ureteral strictures. J Endourol. 2010;24(3):487-91. https://doi.org/10. 1089/end.2009.0138.

25. Kim KS, Choi S, Choi YS, Bae WJ, Hong S-H, Lee JY, et al. Comparison of efficacy and safety between a segmental thermoexpandable metal alloy spiral stent (Memokath 051) and a selfexpandable covered metallic stent (UVENTA) in the management of ureteral obstructions. J Laparoendosc Adv Surg Tech A. 2014;24(8):550-5. https://doi.org/10.1089/lap.2014.0056.

26. Akbarov I, Al-Mahmid M, Pfister D, Heidenreich A. Upper urinary tract decompression using ileal ureter replacement in comparison to endoureteral thermoexpandable stent [Memokath 051]. J Urol. 2017;197(4):E303-4.

27. Bolton EM, Considine S, Moran D, Siddiqui R, Cham A, Nusrat $\mathrm{N}$, et al. Tailored length permanent stents for the treatment of ureteric obstruction. BJU Int. 2015;116:25. https://doi.org/10. 1111/bju.13221.

28. Nam J, Han J, Lee D, Park S, Chung M. Comparison of initial experiences between full-length metallic stent and segmental metallic stent in malignant ureteral obstruction. In: World Congress of Endourology and SWL Annual Meeting 2015. pp P1A457.

29. Arya M, Mostafid H, Patel HR, Kellett MJ, Philp T. The selfexpanding metallic ureteric stent in the long-term management of benign ureteric strictures. BJU Int. 2001;88(4):339-42.

30. Bourdoumis A, Kachrilas S, Kapoor S, Zaman F, Papadopoulos $\mathrm{G}$, Buchholz N, et al. The use of a thermoexpandable metal alloy stent in the minimally invasive management of retroperitoneal fibrosis: a single center experience from the United kingdom. J Endourol. 2014;28(1):96-9. https://doi.org/10.1089/end.2013. 0332 .

31. Boyvat F, Aytekin C, Colak T, Firat A, Karakayali H, Haberal M. Memokath metallic stent in the treatment of transplant kidney ureter stenosis or occlusion. Cardiovasc Interv Radiol. 2005;28(3):326-30. https://doi.org/10.1007/s00270-004-0028-2.

32. Klarskov P, Nordling J, Nielsen JB. Experience with Memokath 051 ureteral stent. Scand J Urol Nephrol. 2005;39(2):169-72. https://doi.org/10.1080/00365590510007720.

33. Papadopoulos GI, Middela S, Srirangam SJ, Szczesniak CA, Rao PN. Use of Memokath 051 metallic stent in the management of ureteral strictures: a single-center experience. Urol Int. 2010;84(3):286-91. https://doi.org/10.1159/000288230.

34. Zaman F, Poullis C, Bach C, Moraitis K, Junaid I, Buchholz N, et al. Use of a segmental thermoexpandable metal alloy stent in the management of malignant ureteric obstruction: a single centre experience in the UK. Urol Int. 2011;87(4):405-10. https://doi. org/10.1159/000326081.

35. Aintree University Hospitals. Cost-effectiveness of using permanent Memokath Stent (MMK) compared to JJ stent (unpublished).

36. Gonzalez LL, Borda AP, Gonzalez ER, Medina JS, Martinez LC, Parra ROA. Decision analysis for economic evaluation of the 
management of chronic obstructive uropathy. Arch Esp Urol. 2011;64(9):875-81.

37. Zaman MF, Goyal A, Bach C, Kachrilas S, Mukherjee K, Junaid I, et al. A cost-effectiveness model for the Memokath 051TM in malignant ureteric obstruction. J Endourol. 2012;26:A434-5. https://doi.org/10.1089/end.2012.2001.

38. Drummond M, Jefferson T. Guidelines for authors and peer reviewers of economic submissions to the BMJ. The BMJ Economic Evaluation Working Party. BMJ. 1996;313(7052):275-83.
39. National Institute for Health and Care Excellence. Medical Technologies Evaluation Programme: process guide. 2011. http:// www.nice.org.uk/Media/Default/About/what-we-do/NICEguidance/NICE-medical-technologies/Medical-technologiesevaluation-programme-process-guide.pdf. Accessed 6 Feb 2015.

40. Department of Health. NHS reference costs 2015-16. London. $2016 . \quad$ https://www.gov.uk/government/publications/nhsreference-costs-collection-guidance-for-2015-to-2016. Accessed 11 May 2017. 